\title{
Synthesis, Crystal Structures and Luminescence Properties of Three New Cadmium 3D Coordination Polymers
}

\author{
Hai-Yan Ju ${ }^{1,2}$, Gang Zhang ${ }^{1,2}$, Ming Yang ${ }^{1,2}$, De-Zheng Liu ${ }^{3, *}$, Yong-Sheng Yang ${ }^{1,2, *(1)}$ and \\ Yan-Bo Zhang 1,2,* \\ 1 School of Chemistry and Engineering, Wuhan Textile University, 1 Textile Road, Wuhan 430073, China; \\ juliesky2001@163.com (H.-Y.J.); prayerzg2019@163.com (G.Z.); yangming491@163.com (M.Y.) \\ 2 Hubei Key Laboratory of Biomass Fibers and Eco-dyeing \& Finishing, Wuhan Textile University, \\ Wuhan 430073, China \\ 3 Hubei Key Laboratory of Power System Design and Test for Electrical Vehicle, Hubei University of Arts and \\ Science, Xiangyang 441053, China \\ * Correspondence: liudezheng@hbuas.edu.cn (D.-Z.L.); ysyang@wtu.edu.cn (Y.-S.Y.); \\ 2006108@wtu.edu.cn (Y.-B.Z.)
}

Academic Editors: Raquel G. Soengas and Humberto Rodríguez-Solla Received: 12 April 2020; Accepted: 18 May 2020; Published: 26 May 2020

\begin{abstract}
The new rigid planar ligand 2,5-bis(3-(pyridine-4-yl)phenyl)thiazolo[5,4-d]thiazole (BPPT) has been synthesized, which is an excellent building block for assembling coordination polymer. Under solvothermal reaction conditions, cadmium ion with BPPT in the presence of various carboxylic acids including (1,1'-biphenyl)-4,4'-dicarboxylic acid (BPDC), isophthalic acid (IP), and benzene-1,3,5-tricarboxylic acid (BTC) gave rise to three coordination complexes, viz, [Cd(BPPT)(BPDA)](BPPT)n (1), [Cd(BPPT) (IP)] $\left(\mathrm{CH}_{3} \mathrm{OH}\right)(2)$, and $\left[\mathrm{Cd}_{3}(\mathrm{BPPT})_{3}(\mathrm{BTC})_{2}\left(\mathrm{H}_{2} \mathrm{O}\right)_{2}\right]$ (3). The structures of $\mathbf{1}, \mathbf{2}$, and $\mathbf{3}$ were characterized by single crystal X-ray diffraction. The IR spectra as well as thermogravimetric and luminescence properties were also investigated. Complex $\mathbf{1}$ is a two-dimensional (2D) network and further stretched to a 3D supramolecular structure through $\pi-\pi$ stacking interaction. The complexes $\mathbf{2}$ and $\mathbf{3}$ show 3D framework. The complexes 1, 2, and $\mathbf{3}$ exhibited luminescence property at room temperature.
\end{abstract}

Keywords: crystal structure; 3D coordination polymer; luminescence properties

\section{Introduction}

In the last twenty years, the design and synthesis of new coordination polymers (CPs) have become an important research area for their intriguing structures and interesting properties, such as catalysis [1-6], gas storage and separation [7-9], photoluminescence [10-12], biomedical uses [13], and other applications [14-16]. In order to make the CPs have special structures and properties, it is necessary to synthesize new ligands [17], in which the heteroaromatic thiazolothiazole unit can be employed as a building block incorporated into organic ligands; the strong $\pi-\pi$ stacking and overlapping of the orbitals in thiazolothiazole unit can afford high electron and hole mobilities, which are crucial properties for efficient charge transfer in optoelectronic materials [18]; and the heteroaromatic thiazolothiazole unit has also shown high luminescence properties [19]. On the other hand, the luminescence properties of coordination polymers with d 10 metal centres $\mathrm{Cd}$ (II) have attracted intense interest because of the potential applications of these compolexes as luminescent sensing materials [20]. Therefore, the design and synthesis of diverse structural $\mathrm{Cd}-\mathrm{MOFs}$ or $\mathrm{Cd}-\mathrm{CPs}$ with optical properties are highly demanded [21,22]. 
Here, we have selected a new ligand, namely 2,5-bis(3-(pyridine-4-yl)phenyl)thiazolo[5,4-d]thiazole (BPPT). In the present report, we used BPPT as a ligand to self-assemble with $\mathrm{Cd}(\mathrm{II})$ ion and obtained a new three-dimensional coordination polymer, namely [Cd(BPPT)(BPDA)](BPPT)n (1), [Cd(BPPT) (IP)] $\left(\mathrm{CH}_{3} \mathrm{OH}\right)(2)$ and $\left[\mathrm{Cd}_{3}(\mathrm{BPPT})_{3}(\mathrm{BTC})_{2}\left(\mathrm{H}_{2} \mathrm{O}\right)_{2}\right]$ (3). The structure was characterized by single crystal $\mathrm{X}$-ray diffraction. The IR spectra as well as thermogravimetric and luminescence properties were also investigated.

\section{Results and Discussion}

\subsection{The Structure of Complex 1}

Single-crystal X-ray diffraction indicated that complex 1 crystallizes in triclinic P-1 space group and displays a two-dimensional (2D) structure, which contains two BPPT, one deprotonated BPDA ligand, and one $\mathrm{Cd}(\mathrm{II})$ cation in the formula unit. A " $\mathrm{Z}$ " shape cavity is formed via the coordination interaction of $\mathrm{Cd}(\mathrm{II})(\mathrm{Cd}-\mathrm{N}$ and $\mathrm{Cd}-\mathrm{O})$ among BPPT and BPDA ligands, which can further propagate to an infinite 2D lamellar framework. As shown in Figure 1a, a 3D layer-type network architecture is formed owing to the presence of $\pi-\pi$ stacking interactions between the layers. Interestingly, there is exactly one BPPT molecule in the " $Z$ " shape cavity, and the closest distance between two parallel $\pi$-stacked BPDA molecules was around $3.56 \AA$ A. Each Cd(II) ion, adopting an octahedral geometry, is equatorially coordinated by four oxygen atoms from two BPDA ligands and two axially coordinated nitrogen atoms from BPPT (Figure 1b). The Cd-O bond lengths range over 2.303(2)-2.461(2) $\AA$ and the Cd-N bond length is 2.351(3) A. Selected bond distances and angles are listed in Table 1. The BPDA ligands and BPPT ligands are considered as linkers to generate a 4-connected 2D network with sql topology (Figure 1c).

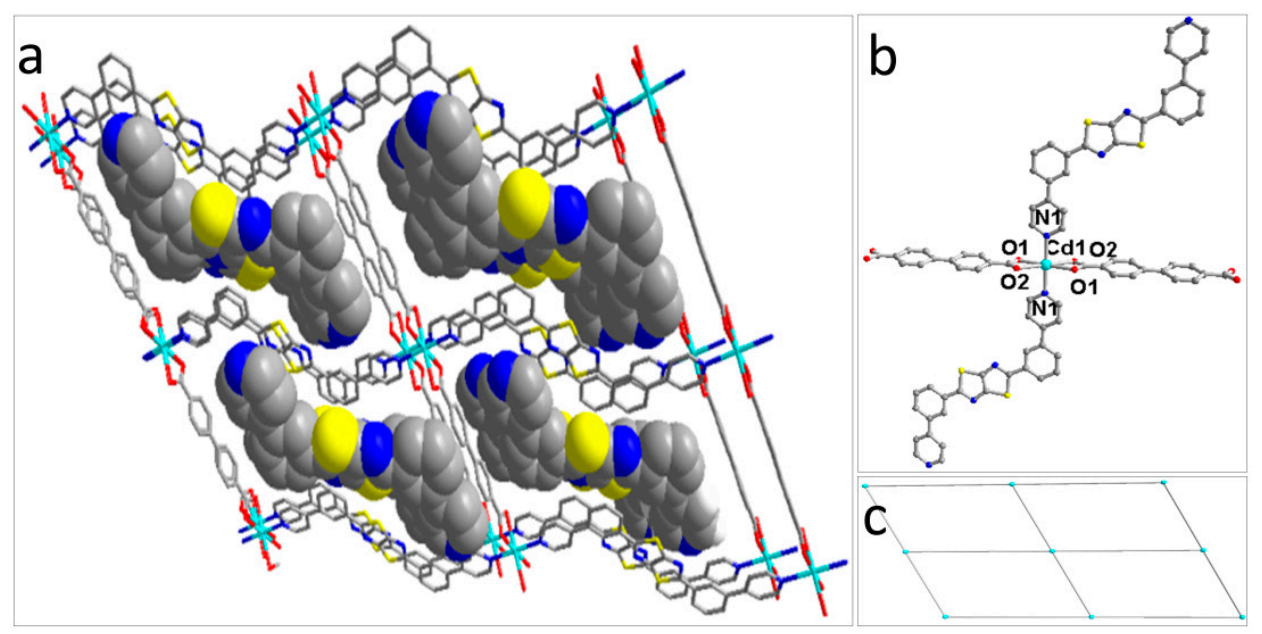

Figure 1. The 3D network of $\mathbf{1}$ (a), the coordination environment of $\mathrm{Cd}(\mathrm{II})$ in $\mathbf{1}(\mathbf{b})$, and the topological network formed in $\mathbf{1}$ (c).

\subsection{The Structure of Complex 2}

The X-ray structural analysis reveals that complex 2 crystallizes in the monoclinic space group P21/c, which is a three-dimensional (3D) coordination polymers constructed from BPPT and IP ligands (Figure 2a). The structural unit is made up of one Cd (II) atom, one BPPT ligand, and one IP ligand. Cd (II) ions are bridged by IP ligands to form a 2D wavelike network along the a axis (Figure 2b). It is noteworthy that the Cd (II) is a seven coordinated ion (Figure 2c), in which five oxygen atoms from IP ligand are in equatorial plane to form a two-dimensional structure (Figure 2b). The Cd-O bond distances vary from $2.366(16)$ to $2.393(17) \AA$. The O-Cd-O bond angles are $53.3(5)^{\circ}-166.5(6)^{\circ}$, respectively. Two pyridyl nitrogen atoms coordinate with $\mathrm{Cd}$ (II) in the axial direction to form a three-dimensional structure with a Cd-N bond distance of $2.317(18) \AA$. The N-Cd-N bond angle is 
$176.5(7)^{\circ}$. That is to say, the $\mathrm{Cd}(\mathrm{II})$ ions are assembled via bridging carboxylate oxygen atoms in a $2 \mathrm{D}$ plane, and these planes are further interconnected by the BPPT ligand, giving rise to a $3 \mathrm{D}$ framework. The closest distance between two parallel $\pi$-stacked DPPZ ligands was around $3.55 \AA$, that is, within the range of $\pi-\pi$ interaction. Topological analysis through the olex, the IP ligands, and BPPT ligands are considered as linkers, then the 3D structure can be classified as a 5-connected network with $\left(4.8^{4}\right)\left(4.6^{4} .8^{4} .10\right)$ topology (Figure $2 \mathrm{~d}$ ).

Table 1. Crystal data and structure refinement for 1,2 , and 3.

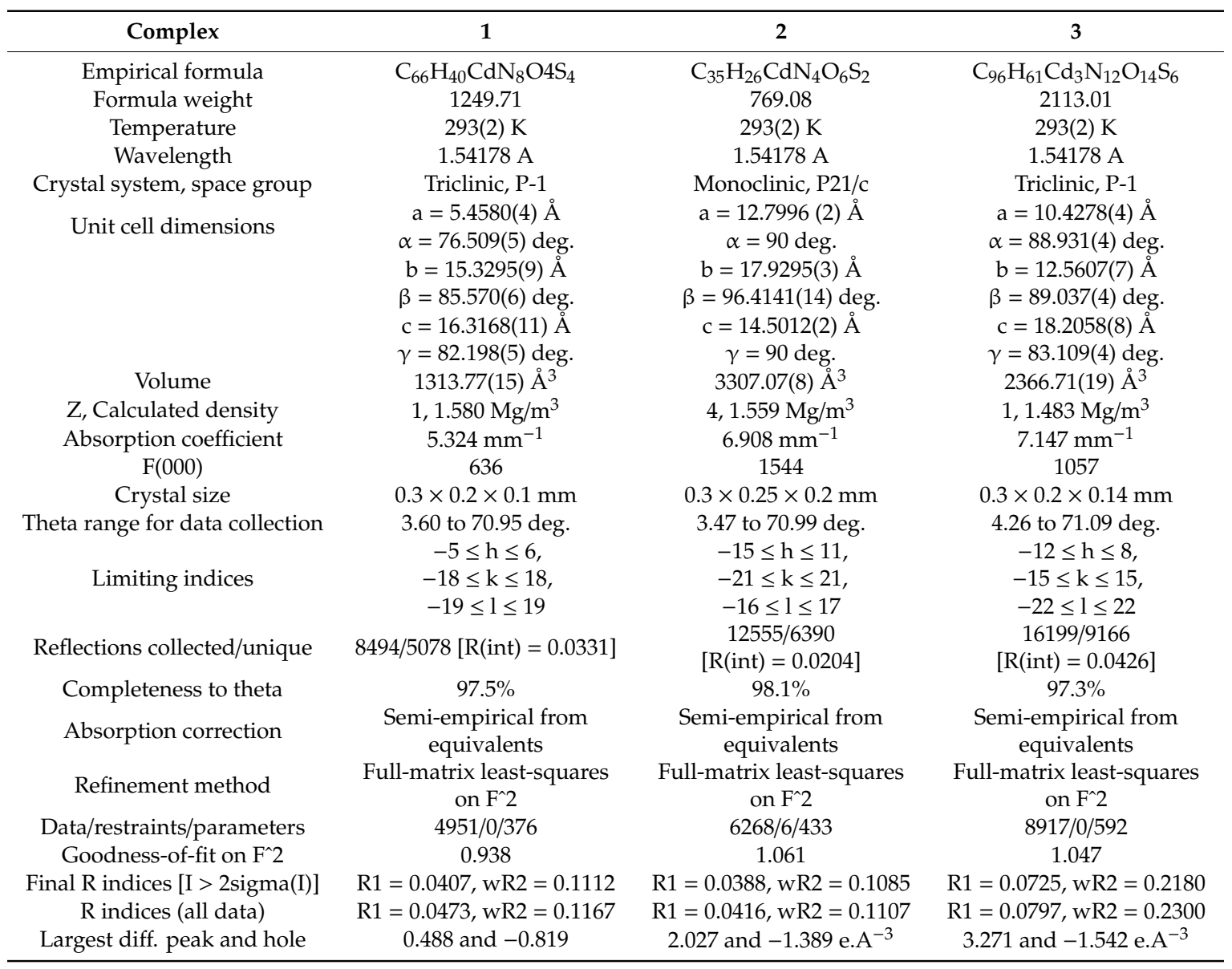

\subsection{The Structure of Complex 3}

According to the single crystal-XRD analysis, complex 3 also crystallized in the monoclinic crystal system with space group of P21/c and its asymmetric unit contains three $\mathrm{Cd}(\mathrm{II})$ ions, three BPPT ligands, two BTC ligands, and two water molecules. Complex 3 has a 3D structure (Figure 3a). The binding of $\mathrm{Cd}(\mathrm{II})$ ions to the organic BTC ligand generates the 2D layer coordination structure, one carboxylic acids group in the BTC coordinates to $\mathrm{Cd}(1)$ ion, and the other two carboxylic groups in the BTC coordinates to $\mathrm{Cd}(2)$ (Figure $3 b$ ). The 2D layer interconnected by the BPPT ligand gives rise to a 3D framework and the closest distance between the two parallel $\pi$-stacked DPTTZ ligands was around $3.57 \AA$. As shown in Figure 3c, the metal atom Cd (1) is six-coordinate and in an octahedral geometry coordination environment with two oxygen atoms $(\mathrm{O} 3, \mathrm{O} 8)$ from BTC ligands, two water molecules, and two nitrogen atoms (N3, N3) from BPPT. The Cd (1)-O3 bond length is 2.253(5) $\AA$, the Cd (1)-O8 bond length is 2.346(9) $\AA$, and the Cd (1)-N bond length is 2.319(6) $\AA$. The O-Cd (1)-O angles are in the range of $82.2(3)^{\circ}-180.00(11)^{\circ}$, the $\mathrm{N}-\mathrm{Cd}(1)-\mathrm{O}$ angles are in the range of $88.7(2)^{\circ}-91.3(2)^{\circ}$, and the $\mathrm{N}-\mathrm{Cd}(1)-\mathrm{N}$ angle is $180.0(3)^{\circ}$. Each Cd (2) ion is located in an octahedral coordination environment. Four oxygen atoms from two BTC ligands and two nitrogen atoms from two BPPT ligands in the 
axial direction, the $\mathrm{Cd}(2)-\mathrm{N}$ bond distance of 2.317(18) $\AA$, and the $\mathrm{N}-\mathrm{Cd}(2)-\mathrm{N}$ bond angle is $176.5(7)^{\circ}$. The Cd (2)-O bond lengths are in the range of 2.255(4) $\AA-2.398(5) \AA$. The O-Cd (2)-O angles are in the range of $55.02(16)^{\circ}-146.95(17)^{\circ}$. The BTC ligands and BPPT ligands are considered as linkers, thus the 3D structure can be classified as a 4, 5-connected network with $\left(4^{2} .6 .8^{4} .9\right)\left(8.9^{3} .10^{2}\right)\left(4^{2} .6^{7} .8\right)$ topology (Figure 3d).

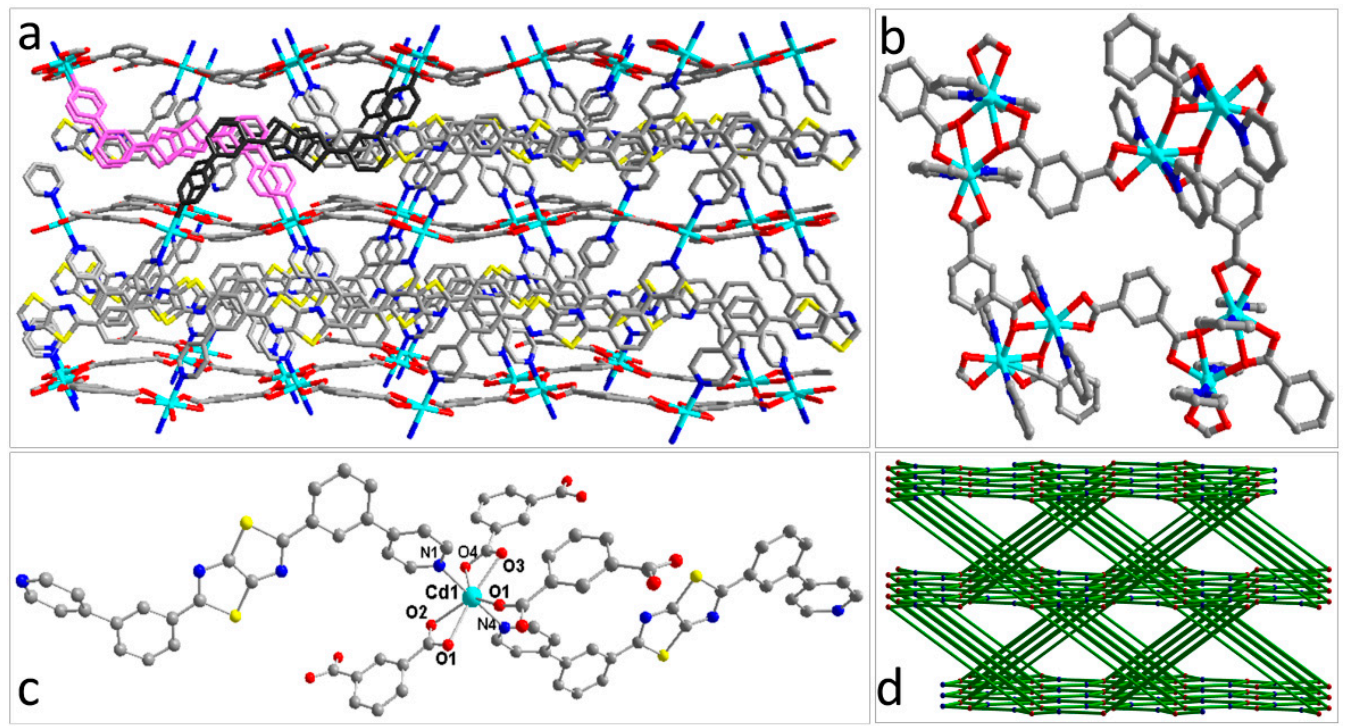

Figure 2. The 3D network of $\mathbf{2}(\mathbf{a})$, the $2 \mathrm{D}[\mathrm{Cd}(\mathrm{IP})] \mathrm{n}$ layer in $\mathbf{2}(\mathbf{b})$, the coordination environment of $\mathrm{Cd}(\mathrm{II})$ in $\mathbf{2}$ (c), and the topological network formed in $\mathbf{2}$ (d); red spheres represent Cd(II) centers, blue spheres represent the isophthalic acid $\left(\mathrm{IP}^{-}\right)$ligands.

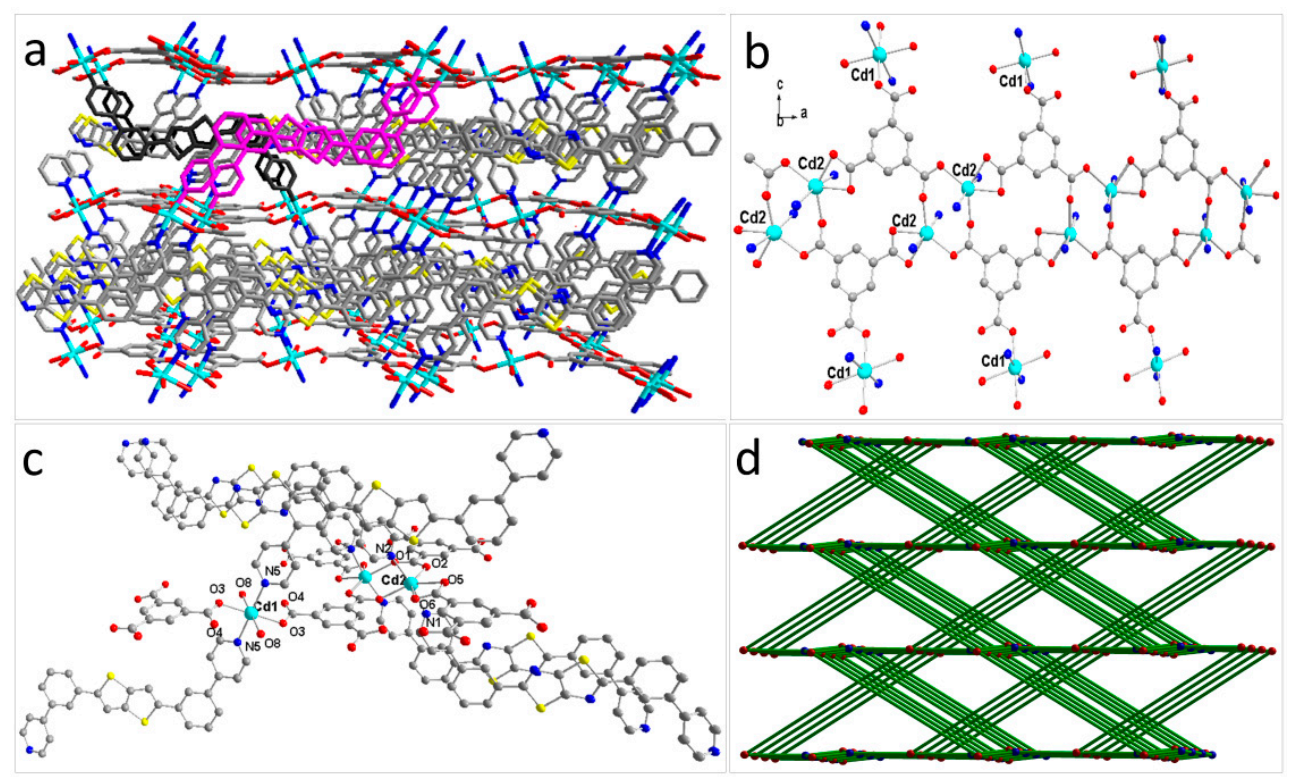

Figure 3. The 3D network of $3(\mathbf{a})$, the $2 \mathrm{D}[\mathrm{Cd}(\mathrm{BTC})] \mathrm{n}$ layer in $\mathbf{3}(\mathbf{b})$, the coordination environment of $\mathrm{Cd}(\mathrm{II})$ in 3 (c), and the topological network formed in $\mathbf{3}$ (d); red spheres represent Cd(II) centers, blue spheres represent the benzene-1,3,5-tricarboxylic acid $\left(\mathrm{BTC}^{-}\right)$ligands.

\subsection{TGA}

TGA was conducted to investigate the thermal stability of complexes 1, 2, and $\mathbf{3}$. As shown in Figure 4, the TG curve of 1 displayed no obvious weight loss before $380^{\circ} \mathrm{C}$, the weight loss of $49.1 \%$ can be distributed to the removal of BPPT molecule in the "Z" shape cavity (calcd. 35.9\%), and the 
framework to decompose at $380-445^{\circ} \mathrm{C}$, the remaining weight corresponds to the constitution of $\mathrm{CdO}$ (calcd. $11.8 \%$, found $9.2 \%$ ) at $700{ }^{\circ} \mathrm{C}$. The TGA for complex 2 shows a weight loss of $3.8 \%$ (calculated $4.1 \%$ ) before $75{ }^{\circ} \mathrm{C}$, which is associated with the loss of one free methanol molecule. When the temperature reaches $400{ }^{\circ} \mathrm{C}$, the framework of 2 begins to break down gradually. The weight loss of $85.5 \%$ (calculated $81.1 \%$ ) at $700{ }^{\circ} \mathrm{C}$ can be ascribed to the decomposition of organic matters in complex 2. According to the TGA results, complex 3 exhibited no obvious weight loss before $310{ }^{\circ} \mathrm{C}$. After that temperature, the framework begins to decompose. The weight loss of $84.1 \%$ (calculated $79.4 \%$ ) at $700{ }^{\circ} \mathrm{C}$ can be ascribed to the decomposition of organic matters in complex 3.

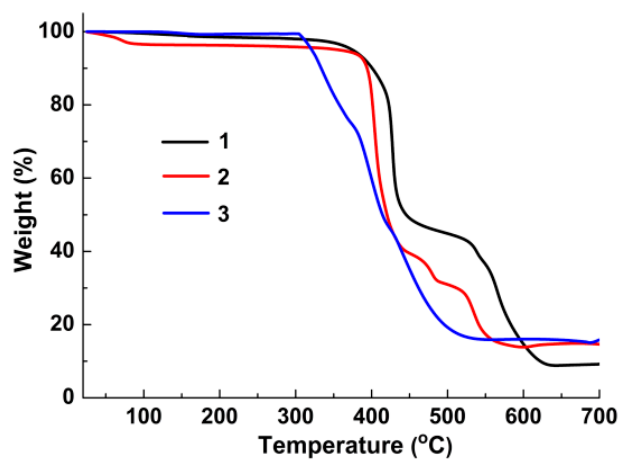

Figure 4. Thermal gravimetric analysis (TGA) curves of complexes 1-3.

\subsection{IR Analysis}

In the IR spectra of complexes 1, 2, and 3 (Figure 5), the broad bands at about $3482 \mathrm{~cm}^{-1}$ for 2 and $3399 \mathrm{~cm}^{-1}$ for 3 are assigned to the presence of methanol (2) water molecules (3). All three complexes displayed similar FT-IR spectra with only a little variation in the peak position with regards to the $-\mathrm{C}=\mathrm{N}\left(1019 \mathrm{~cm}^{-1}\right)$ and $-\mathrm{C}-\mathrm{S}$ bonds $\left(693 \mathrm{~cm}^{-1}\right.$ and $\left.650 \mathrm{~cm}^{-1}\right)$ of the BPPT [23]. The characteristic peaks of the deprotonated -COO- symmetry band and the asymmetric band appeared at $1600 \mathrm{~cm}^{-1}$ and $1423 \mathrm{~cm}^{-1}$ for 2 and $1609 \mathrm{~cm}^{-1}$ and $1438 \mathrm{~cm}^{-1}$ for 3 , respectively.

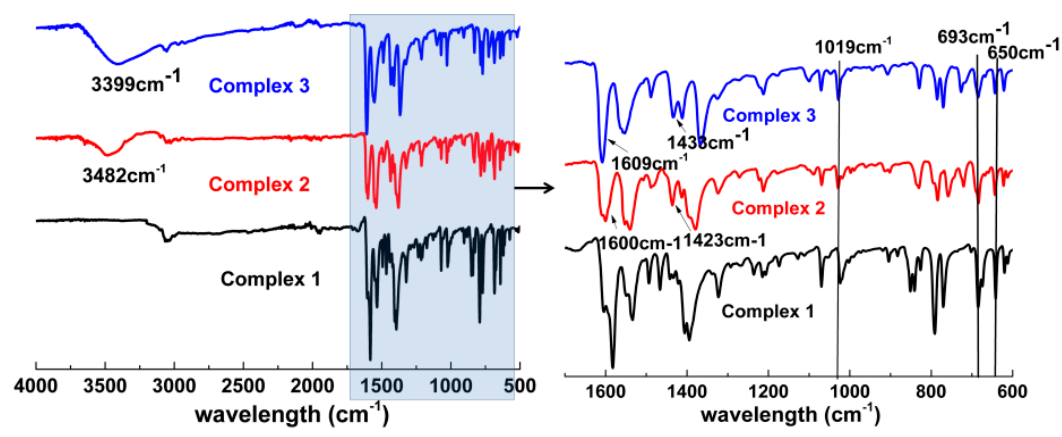

Figure 5. Comparison of FT-IR spectrum of complexes 1, 2, and 3.

\subsection{UV/Vis Analysis}

From the spectrum of UV/vis (Figure 6), the maximum absorption of BPPT, 1, 2, and 3 occurred at $330 \mathrm{~nm}, 340 \mathrm{~nm}, 330 \mathrm{~nm}$, and $344 \mathrm{~nm}$, respectively. The bands could be assigned to characteristic $\pi-\pi^{*}$ transitions centered on BPPT. Compared with the free ligand BPPT, the absorption peaks of $\mathbf{1}$, 2 , and 3 have slightly red-shift, probably attributed to the coordination of the ligands to the Cd ion, which effectively increases the conjugated extent of the complexes [24]. 


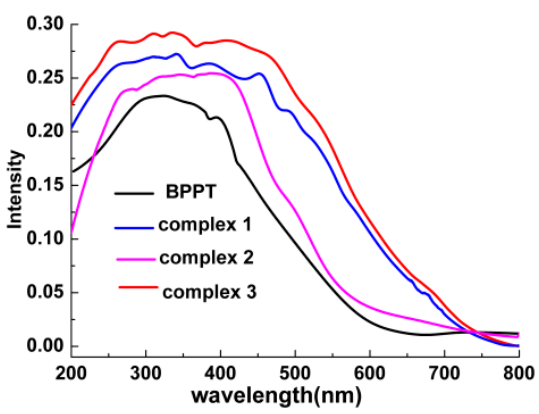

Figure 6. UV/vis spectrogram of 2, 5-bis(3-(pyridine-4-yl)phenyl)thiazolo[5,4-d]thiazole (BPPT) as well as complexes 1, 2, and 3 in the solid state.

\subsection{Luminescence Properties}

The luminescence properties of complexes $\mathbf{1}, \mathbf{2}$, and $\mathbf{3}$ were investigated in the solid state at room temperature. The emission spectra are shown in Figure 7, and the complexes 1, 2, and 3 exhibit luminescence properties, with an emission at $483 \mathrm{~nm}$ (excited at $340 \mathrm{~nm}$ ), $463 \mathrm{~nm}$ (excited at $330 \mathrm{~nm}$ ), and $489 \mathrm{~nm}$ (excited at $344 \mathrm{~nm}$ ), respectively. To understand the nature of the emission spectra, the luminescence property of free BPPT ligand was also investigated in the solid state under the same experimental conditions. The BPPT ligand exhibits one emission band at $455 \mathrm{~nm}$ upon excitation at $330 \mathrm{~nm}$. This suggests that the emission of $\mathbf{1}, \mathbf{2}$, and $\mathbf{3}$ originated from the $\pi-\pi^{*}$ electronic transition of the ligand [25]. By comparing the emission spectra of complexes 1, 2, and $\mathbf{3}$ and the free BPPT ligand, we can conclude that the enhancement of luminescence in $\mathbf{1}, \mathbf{2}$, and 3 may be attributed to the ligation of ligand to the metal center, which effectively increases the rigidity and reduces the loss of energy by radiation less decay $[26,27]$. A detailed spectroscopic study of a possible structure-related luminescent is underway.

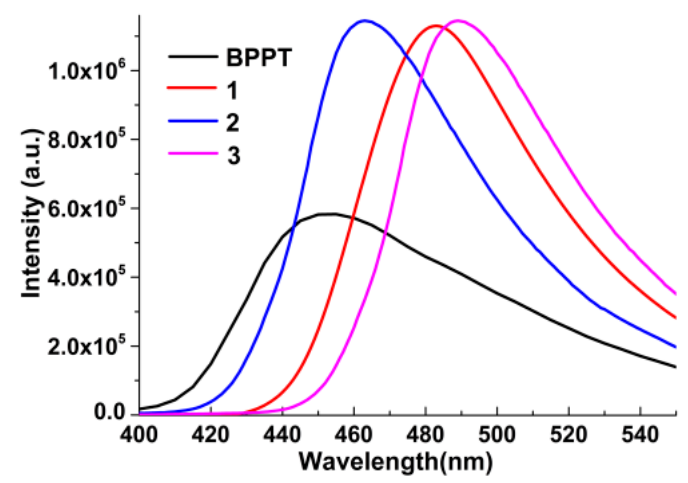

Figure 7. The emission spectra of BPPT, 1, 2, and 3 in the solid state at room temperature.

\section{Experiment}

\subsection{Material and Physical Measurements}

The organic ligand BPPT was synthesized by modifying the reported procedure using 3-(pyridine-4-yl)benzaldehyde [28]. 3-Bromobenzaldehyde, 4-Pyridineboronic acid, dithiooxamide (Macklin Biochemical Co., Ltd., Shanghai, China) and other reagents (Fuyu Chemical Co., Ltd., Tianjin, China), were used without further purification. The structures of ligands used in the syntheses of the coordination polymers are shown in Scheme 1. Elemental analyses for $\mathrm{C}, \mathrm{H}$, and $\mathrm{N}$ were performed on a Perkin-Elmer 240C Elemental Analyzer (PerkinElmer, Waltham, MA, USA) at the analysis center of Nanjing University. FT-IR (Fourier transform infrared) spectra were recorded in the range of $400-4000 \mathrm{~cm}^{-1}$ on a Bruker Vector 22 FT-IR spectrophotometer (Bruker, Karlsruhe, Germany) using $\mathrm{KBr}$ pellets. Powder X-ray diffraction (PXRD) measurements were carried out on 
a Bruker $\mathrm{D}_{8}$ Advance X-ray diffractometer (Bruker, Karlsruhe, Germany) using Cu-K $\alpha$ radiation $(\lambda=1.5418 \AA$ ). Thermal gravimetric analyses (TGAs) were taken on a Mettler-Toledo thermal analyzer (Mettler-Toledo, Greifensee, Switzerland) under an N2 atmosphere with a heating rate of $10{ }^{\circ} \mathrm{C} \cdot \mathrm{min}^{-1}$. The luminescence spectra were measured on a Perkin Elmer LS-55 fluorescence spectrophotometer (PerkinElmer, Waltham, MA, USA).
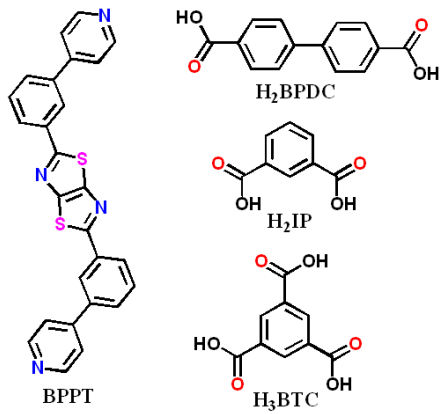

Scheme 1. The structures of ligands used in the syntheses of the coordination polymers. BPPT, 2 , 5-bis(3-(pyridine-4-yl)phenyl)thiazolo[5,4-d]thiazole; BPDC, (1,1'-biphenyl)-4,4'-dicarboxylic acid; IP, isophthalic acid; BTC, benzene-1,3,5-tricarboxylic acid.

\subsection{Synthesis of 3-(Pyridine-4-yl) Benzaldehyde}

3-Bromobenzaldehyde (1.98 g, $10.72 \mathrm{mmol})$ was dissolved in $20 \mathrm{~mL}$ of 1, 4-dioxane and $20 \mathrm{~mL}$ of water. Then, 4-Pyridineboronic acid $(1.26 \mathrm{~g}, 10.25 \mathrm{mmol})$ was added and dissolved, followed by the addition of $\mathrm{K}_{2} \mathrm{CO}_{3}(4.2 \mathrm{~g}, 17.36 \mathrm{mmol})$ and $\mathrm{Pd}\left(\mathrm{PPh}_{3}\right)_{4}(290 \mathrm{mg}, 0.25 \mathrm{mmol})$. The mixture was refluxed under the protection of $\mathrm{N}_{2}$ gas and stirred for $72 \mathrm{~h}$ at $80{ }^{\circ} \mathrm{C}$. After cooling to room temperature, the solvent was removed under reduced pressure to obtain the white solid. The residue was purified by silica gel column chromatography using petroleum ether and ethyl acetate $(v / v, 1 / 1)$ as eluent to afford 3-(pyridine-4-yl) benzaldehyde. (Yield, 81.0\%). ${ }^{1} \mathrm{H}$ NMR (400 MHz, $\left.\mathrm{CDCl}_{3}\right) \delta 10.16-10.08$ (m, $1 \mathrm{H}), 8.72(\mathrm{~d}, J=5.5 \mathrm{~Hz}, 2 \mathrm{H}), 8.16(\mathrm{~s}, 1 \mathrm{H}), 7.94(\mathrm{dd}, J=19.5,7.7 \mathrm{~Hz}, 2 \mathrm{H}), 7.69(\mathrm{t}, J=7.7 \mathrm{~Hz}, 1 \mathrm{H}), 7.55$ $(\mathrm{t}, J=6.5 \mathrm{~Hz}, 2 \mathrm{H})$. IR (KBr pellet $\left.\mathrm{cm}^{-1}\right): 3029(\mathrm{~m}), 2826(\mathrm{~m}), 2730(\mathrm{~m}), 1949(\mathrm{~s}), 1690(\mathrm{~s}), 1601(\mathrm{~s}), 1583(\mathrm{~s})$, 1413(s), 1302(s), 1189(s), 789(s), 654(m), 613(m), 579(m).

\subsection{Synthesis of 2,5-Bis(3-(pyridine-4-yl)phenyl)thiazolo[5,4-d]thiazole (BPPT)}

A mixture of 3-(pyridine-4-yl)benzaldehyde $(1.83 \mathrm{~g}, 10.0 \mathrm{mmol})$ and dithiooxamide $(0.60 \mathrm{~g}$, $5.0 \mathrm{mmol}$ ) in DMF (20 mL) was stirred at $150{ }^{\circ} \mathrm{C}$ for $24 \mathrm{~h}$. The residue was purified by silica gel column chromatography using dichloromethane (DCM) as eluent to afford L (yield, 81.0\%). ${ }^{1} \mathrm{H}$ NMR (400 $\left.\mathrm{MHz}_{2} \mathrm{CHCl}_{3}\right):{ }^{1} \mathrm{H} \mathrm{NMR}\left(400 \mathrm{MHz}, \mathrm{CDCl}_{3}\right) \delta 8.73(\mathrm{dd}, J=4.5,1.6 \mathrm{~Hz}, 2 \mathrm{H}), 8.32(\mathrm{t}, J=1.7 \mathrm{~Hz}, 1 \mathrm{H}), 8.05$ $(\mathrm{ddd}, J=13.4,7.8,6.4 \mathrm{~Hz}, 1 \mathrm{H}), 7.79-7.70(\mathrm{~m}, 1 \mathrm{H}), 7.67-7.57(\mathrm{~m}, 3 \mathrm{H}), 2.95(\mathrm{dd}, J=28.8,22.7 \mathrm{~Hz}, 1 \mathrm{H})$. IR(KBr pellet $\left.\mathrm{cm}^{-1}\right)$ : 3033(m), 1661(w), 1597(s), 1533(m), 1469(m), 1286(m), 1222(m), 1020(m), 791(s), 673(s), 609(s).

\subsection{Synthesis of $[C d(B P P T)(B P D A)](B P P T) n(\mathbf{1})$}

A mixture of BPPT $(15.0 \mathrm{mg}, 0.03 \mathrm{mmol}), \mathrm{H}_{2}$ BPDA $(7.2 \mathrm{mg}, 0.03 \mathrm{mmol}), \mathrm{Cd}\left(\mathrm{ClO}_{4}\right)_{2}(2.1 \mathrm{mg}$, $0.06 \mathrm{mmol})$, and DMF/water $(15 \mathrm{~mL}, 1: 1 \mathrm{v} / \mathrm{v})$ was placed in a $20 \mathrm{~mL}$ Teflon-lined stainless steel autoclave. The mixture was heated under autogenous pressure at $433 \mathrm{~K}$ for $72 \mathrm{~h}$ and then cooled to room temperature. Yellow block-shaped crystals were collected by filtration, washed with $\mathrm{H}_{2} \mathrm{O}$, and dried in air (yield 67\%, based on BPPT). Analysis calculated for $\mathrm{C}_{66} \mathrm{H}_{40} \mathrm{CdN}_{8} \mathrm{O}_{4} \mathrm{~S}_{4}$ : C 63.43, $\mathrm{H} 3.23, \mathrm{~N} 8.97 \%$; found: C 63.40, H 3.27, N 8.96\%. IR (KBr pellet $\left.\mathrm{cm}^{-1}\right)$ : 3043(w), 1569(s), 1524(s), 1451(m), 1386(s), 1323(m), 1203(w), 838(m), 773(s), 691(m), 650(m), 627(m). 


\subsection{Synthesis of $[\mathrm{Cd}(\mathrm{BPPT})(\mathrm{IP})]\left(\mathrm{CH}_{3} \mathrm{OH}\right)(\mathbf{2})$}

A mixture of BPPT (15.0 mg, $0.03 \mathrm{mmol}), \mathrm{H}_{2} \mathrm{IP}(4.8 \mathrm{mg}, 0.03 \mathrm{mmol}), \mathrm{Cd}\left(\mathrm{NO}_{3}\right)_{2}(2.1 \mathrm{mg}, 0.06 \mathrm{mmol})$, and methanol/water $(15 \mathrm{~mL}, 1: 1 \mathrm{v} / \mathrm{v})$ was placed in a $20 \mathrm{~mL}$ Teflon-lined stainless steel autoclave. The mixture was heated under autogenous pressure at $433 \mathrm{~K}$ for $72 \mathrm{~h}$ and then cooled to room temperature. Yellow block-shaped crystals were collected by filtration, washed with $\mathrm{H}_{2} \mathrm{O}$, and dried in air (yield 67\%, based on BPPT). Analysis calculated for $\mathrm{C}_{35} \mathrm{H}_{26} \mathrm{CdN}_{4} \mathrm{O}_{6} \mathrm{~S}_{2}$ : C 54.23, H 3.38, N 7.23\%; found: C 54.18, H 3.42, N 7.24\%. IR (KBr pellet $\left.\mathrm{cm}^{-1}\right)$ : 3482(m), 3024(w), 1600(s), 1587(s), 1551(s), 1435(m), 1423(m), 1377(s), 1203(m), 1057(m), 1020(w), 755(m), 690(m), 673(m).

\subsection{Synthesis of $\left[\mathrm{Cd}_{3}(\mathrm{BPPT})_{3}(\mathrm{BTC})_{2}\left(\mathrm{H}_{2} \mathrm{O}\right)_{2}\right](3)$}

A mixture of BPPT (15.0 mg, $0.03 \mathrm{mmol}), \mathrm{H}_{3} \mathrm{BTC}(6.3 \mathrm{mg}, 0.03 \mathrm{mmol}), \mathrm{Cd}\left(\mathrm{NO}_{3}\right)_{2}(21.0 \mathrm{mg}$, $0.06 \mathrm{mmol})$, and ethanol/water $(15 \mathrm{~mL}, 1: 1 \mathrm{v} / \mathrm{v})$ was placed in a $20 \mathrm{~mL}$ Teflon-lined stainless steel autoclave. The mixture was heated under autogenous pressure at $433 \mathrm{~K}$ for $72 \mathrm{~h}$ and then cooled to room temperature. Yellow block-shaped crystals were collected by filtration, washed with $\mathrm{H}_{2} \mathrm{O}$, and dried in air (yield 67\%, based on BPPT). Analysis calculated for $\mathrm{C}_{96} \mathrm{H}_{61} \mathrm{Cd}_{3} \mathrm{~N}_{12} \mathrm{O}_{14} \mathrm{~S}_{6}$ : C 53.98, H 2.88, N 7.87\%; found: C 53.95, H 2.95, N 7.83\%. IR (KBr pellet $\left.\mathrm{cm}^{-1}\right)$ : 3399(w), 1609(s), 1552(s), 1488(w), 1433(m), 1414(m), 1367(m), 1213(w), 1020(w), 791(w), 690(m), 682(w), 618(w).

\subsection{X-Ray Crystallography}

Diffraction data for the complex were collected at 293 (2) K, with a Bruker Smart 1000 CCD diffractometer using Mo-K $\alpha$ radiation $(\lambda=0.71073 \AA)$ with the $\omega-2 \theta$ scan technique. An empirical absorption correction was applied to raw intensities [29]. The structure was solved by direct methods (SHELX-97) and refined with full-matrix least-squares technique on $\mathrm{F}_{2}$ using the SHELX-97 [30]. The hydrogen atoms were added theoretically, and riding on the concerned atoms and refined with fixed thermal factors. Crystal data, data collection, and structure refinement details are summarized in Table 1. Suitable single crystals of $\mathbf{1}, \mathbf{2}$, and $\mathbf{3}$ were selected and mounted in air onto thin glass fibers. In these structures, $\mathrm{H}$ atoms bonded to $\mathrm{C}$ atoms were treated as riding in geometrically idealized positions, with $\mathrm{C}-\mathrm{H}=0.93 \AA$ and $U_{\text {iso }}(\mathrm{H})=1.2 U$ eq $(\mathrm{C})$, and the selected bond lengths and angles with their estimated standard deviations are listed in Table 2.

Table 2. Selected bond lengths $(\AA)$ and bond angles $\left(^{\circ}\right)$ of complex 1, 2, and 3.

\begin{tabular}{|c|c|c|c|c|c|}
\hline \multicolumn{6}{|c|}{ Complex 1} \\
\hline Bond & Dist. & Bond & Dist. & Bond & Dist. \\
\hline $\mathrm{Cd}(1)-\mathrm{O}(1)$ & $2.303(2)$ & $\mathrm{Cd}(1)-\mathrm{N}(1)$ & $2.351(3)$ & $\mathrm{Cd}(1)-\mathrm{O}(2)$ & $2.461(2)$ \\
\hline Angle & $\left({ }^{\circ}\right)$ & Angle & $\left({ }^{\circ}\right)$ & Angle & $\left(^{\circ}\right)$ \\
\hline $\mathrm{O}(1) \# 2-\mathrm{Cd}(1)-\mathrm{O}(1)$ & $180.00(12)$ & $\mathrm{O}(1) \# 2-\mathrm{Cd}(1)-\mathrm{N}(1)$ & $89.89(9)$ & $\mathrm{O}(1)-\mathrm{Cd}(1)-\mathrm{N}(1)$ & $90.11(9)$ \\
\hline $\mathrm{O}(1) \# 2-\mathrm{Cd}(1)-\mathrm{N}(1) \# 2$ & $90.11(9)$ & $\mathrm{O}(1)-\mathrm{Cd}(1)-\mathrm{N}(1) \# 2$ & $89.89(9)$ & $\mathrm{N}(1)-\mathrm{Cd}(1)-\mathrm{N}(1) \# 2$ & 180.0 \\
\hline $\mathrm{O}(1) \# 2-\mathrm{Cd}(1)-\mathrm{O}(2)$ & $124.89(8)$ & $\mathrm{O}(1)-\mathrm{Cd}(1)-\mathrm{O}(2)$ & $55.11(8)$ & $\mathrm{N}(1)-\mathrm{Cd}(1)-\mathrm{O}(2)$ & $89.93(9)$ \\
\hline $\mathrm{N}(1) \# 2-\mathrm{Cd}(1)-\mathrm{O}(2)$ & $90.07(9)$ & $\mathrm{O}(1) \# 2-\mathrm{Cd}(1)-\mathrm{O}(2) \# 2$ & $55.11(8)$ & $\mathrm{O}(1)-\mathrm{Cd}(1)-\mathrm{O}(2) \# 2$ & $124.89(8)$ \\
\hline $\mathrm{N}(1)-\mathrm{Cd}(1)-\mathrm{O}(2) \# 2$ & $90.07(9)$ & & & & \\
\hline \multicolumn{6}{|c|}{ Complex 2} \\
\hline Bond & Dist. & Bond & Dist. & Bond & Dist. \\
\hline $\mathrm{N}(4)-\mathrm{Cd}(1) \# 1$ & $2.317(18)$ & $\mathrm{O}(3)-\mathrm{Cd}(1) \# 2$ & $2.381(17)$ & $\mathrm{Cd}(1)-\mathrm{N}(4) \# 3$ & $2.317(18)$ \\
\hline $\mathrm{Cd}(1)-\mathrm{N}(1)$ & $2.324(18)$ & $\mathrm{Cd}(1)-\mathrm{O}(2)$ & $2.364(16)$ & $\mathrm{Cd}(1)-\mathrm{O}(1) \# 4$ & $2.366(16)$ \\
\hline $\mathrm{Cd}(1)-\mathrm{O}(3) \# 5$ & $2.381(17)$ & $\mathrm{Cd}(1)-\mathrm{O}(4) \# 5$ & $2.393(17)$ & $\mathrm{Cd}(1)-\mathrm{O}(1)$ & $2.522(16)$ \\
\hline Angle & $\left({ }^{\circ}\right)$ & Angle & $\left.{ }^{\circ}\right)$ & Angle & $\left({ }^{\circ}\right)$ \\
\hline $\mathrm{N}(4) \# 3-\mathrm{Cd}(1)-\mathrm{N}(1)$ & $176.5(7)$ & $\mathrm{N}(4) \# 3-\mathrm{Cd}(1)-\mathrm{O}(2)$ & $94.7(6)$ & $\mathrm{N}(1)-\mathrm{Cd}(1)-\mathrm{O}(2)$ & $87.4(6)$ \\
\hline
\end{tabular}


Table 2. Cont

\begin{tabular}{|c|c|c|c|c|c|}
\hline $\mathrm{N}(4) \# 3-\mathrm{Cd}(1)-\mathrm{O}(1) \# 4$ & $90.8(6)$ & $\mathrm{N}(1)-\mathrm{Cd}(1)-\mathrm{O}(1) \# 4$ & $85.7(6)$ & $\mathrm{O}(2)-\mathrm{Cd}(1)-\mathrm{O}(1) \# 4$ & $125.9(5)$ \\
\hline $\mathrm{N}(4) \# 3-\mathrm{Cd}(1)-\mathrm{O}(3) \# 5$ & $86.5(7)$ & $\mathrm{N}(1)-\mathrm{Cd}(1)-\mathrm{O}(3) \# 5$ & $93.7(7)$ & $\mathrm{O}(2)-\mathrm{Cd}(1)-\mathrm{O}(3) \# 5$ & $140.2(6)$ \\
\hline $\mathrm{O}(1) \# 4-\mathrm{Cd}(1)-\mathrm{O}(3) \# 5$ & $93.7(6)$ & $\mathrm{N}(4) \# 3-\mathrm{Cd}(1)-\mathrm{O}(4) \# 5$ & $90.3(7)$ & $\mathrm{N}(1)-\mathrm{Cd}(1)-\mathrm{O}(4) \# 5$ & $92.7(7)$ \\
\hline $\mathrm{O}(2)-\mathrm{Cd}(1)-\mathrm{O}(4) \# 5$ & $85.7(6)$ & $\mathrm{O}(1) \# 4-\mathrm{Cd}(1)-\mathrm{O}(4) \# 5$ & $148.2(6)$ & $\mathrm{O}(3) \# 5-\mathrm{Cd}(1)-\mathrm{O}(4) \# 5$ & $54.6(6)$ \\
\hline $\mathrm{N}(4) \# 3-\mathrm{Cd}(1)-\mathrm{O}(1)$ & $92.9(6)$ & $\mathrm{N}(1)-\mathrm{Cd}(1)-\mathrm{O}(1)$ & $86.1(6)$ & $\mathrm{O}(2)-\mathrm{Cd}(1)-\mathrm{O}(1)$ & $53.3(5)$ \\
\hline $\mathrm{O}(1) \# 4-\mathrm{Cd}(1)-\mathrm{O}(1)$ & $72.7(6)$ & $\mathrm{O}(3) \# 5-\mathrm{Cd}(1)-\mathrm{O}(1)$ & $166.5(6)$ & $\mathrm{O}(4) \# 5-\mathrm{Cd}(1)-\mathrm{O}(1)$ & 139.0(5) \\
\hline \multicolumn{6}{|c|}{ Complex 3} \\
\hline Bond & Dist. & Bond & Dist. & Bond & Dist. \\
\hline $\mathrm{Cd}(1)-\mathrm{O}(3)$ & $2.253(5)$ & $\mathrm{Cd}(1)-\mathrm{N}(5)$ & $2.319(6)$ & $\mathrm{Cd}(1)-\mathrm{O}(8)$ & $2.346(9)$ \\
\hline $\mathrm{Cd}(2)-\mathrm{O}(2) \# 2$ & $2.255(4)$ & $\mathrm{Cd}(2)-\mathrm{N}(2)$ & $2.303(5)$ & $\mathrm{Cd}(2)-\mathrm{O}(1)$ & $2.309(4)$ \\
\hline $\mathrm{Cd}(2)-\mathrm{N}(1)$ & $2.325(6)$ & $\mathrm{Cd}(2)-\mathrm{O}(6) \# 3$ & $2.367(5)$ & $\mathrm{Cd}(2)-\mathrm{O}(5) \# 3$ & $2.398(5)$ \\
\hline Angle & $\left({ }^{\circ}\right)$ & Angle & $\left(^{\circ}\right)$ & Angle & $\left(^{\circ}\right)$ \\
\hline $\mathrm{O}(3) \# 1-\mathrm{Cd}(1)-\mathrm{O}(3)$ & $180.00(11)$ & $\mathrm{O}(3) \# 1-\mathrm{Cd}(1)-\mathrm{N}(5) \# 1$ & $88.7(2)$ & $\mathrm{O}(3)-\mathrm{Cd}(1)-\mathrm{N}(5) \# 1$ & $91.3(2)$ \\
\hline $\mathrm{O}(3) \# 1-\mathrm{Cd}(1)-\mathrm{N}(5)$ & $91.3(2)$ & $\mathrm{O}(3)-\mathrm{Cd}(1)-\mathrm{N}(5)$ & $88.7(2)$ & $\mathrm{N}(5) \# 1-\mathrm{Cd}(1)-\mathrm{N}(5)$ & $180.0(3)$ \\
\hline $\mathrm{O}(3) \# 1-\mathrm{Cd}(1)-\mathrm{O}(8) \# 1$ & $82.2(3)$ & $\mathrm{O}(3)-\mathrm{Cd}(1)-\mathrm{O}(8) \# 1$ & $97.8(3)$ & $\mathrm{N}(5) \# 1-\mathrm{Cd}(1)-\mathrm{O}(8) \# 1$ & $90.0(4)$ \\
\hline $\mathrm{N}(5)-\mathrm{Cd}(1)-\mathrm{O}(8) \# 1$ & $90.0(4)$ & $\mathrm{O}(3) \# 1-\mathrm{Cd}(1)-\mathrm{O}(8)$ & $97.8(3)$ & $\mathrm{O}(3)-\mathrm{Cd}(1)-\mathrm{O}(8)$ & $82.2(3)$ \\
\hline $\mathrm{N}(5) \# 1-\mathrm{Cd}(1)-\mathrm{O}(8)$ & $90.0(4)$ & $\mathrm{N}(5)-\mathrm{Cd}(1)-\mathrm{O}(8)$ & $90.0(4)$ & $\mathrm{O}(8) \# 1-\mathrm{Cd}(1)-\mathrm{O}(8)$ & $180.000(1)$ \\
\hline $\mathrm{O}(2) \# 2-\mathrm{Cd}(2)-\mathrm{N}(2)$ & 95.93(19) & $\mathrm{O}(2) \# 2-\mathrm{Cd}(2)-\mathrm{O}(1)$ & $122.65(17)$ & $\mathrm{N}(2)-\mathrm{Cd}(2)-\mathrm{O}(1)$ & $87.30(18)$ \\
\hline $\mathrm{O}(2) \# 2-\mathrm{Cd}(2)-\mathrm{N}(1)$ & $88.3(2)$ & $\mathrm{N}(2)-\mathrm{Cd}(2)-\mathrm{N}(1)$ & $71.0(2)$ & $\mathrm{O}(1)-\mathrm{Cd}(2)-\mathrm{N}(1)$ & $83.8(2)$ \\
\hline $\mathrm{O}(2) \# 2-\mathrm{Cd}(2)-\mathrm{O}(6) \# 3$ & $146.95(17)$ & $\mathrm{N}(2)-\mathrm{Cd}(2)-\mathrm{O}(6) \# 3$ & $90.31(18)$ & $\mathrm{O}(1)-\mathrm{Cd}(2)-\mathrm{O}(6) \# 3$ & $89.97(17)$ \\
\hline $\mathrm{N}(1)-\mathrm{Cd}(2)-\mathrm{O}(6) \# 3$ & $90.4(2)$ & $\mathrm{O}(2) \# 2-\mathrm{Cd}(2)-\mathrm{O}(5) \# 3$ & 91.94(17) & $\mathrm{N}(2)-\mathrm{Cd}(2)-\mathrm{O}(5) \# 3$ & $99.5(2)$ \\
\hline $\mathrm{O}(1)-\mathrm{Cd}(2)-\mathrm{O}(5) \# 3$ & $144.07(16)$ & $\mathrm{N}(1)-\mathrm{Cd}(2)-\mathrm{O}(5) \# 3$ & $88.3(2)$ & $\mathrm{O}(6) \# 3-\mathrm{Cd}(2)-\mathrm{O}(5) \# 3$ & $55.02(16)$ \\
\hline
\end{tabular}

\section{Conclusions}

The new rigid planar ligand BPPT has been synthesized, by introducing different rigid carboxylic acids BPDC, IP, and BTC as auxiliary ligands; three Cd(II) CPs have been synthesized successfully under solvothermal conditions. The complexes 1, 2, and 3 show a 3D framework and have good thermal stability. In addition, complexes 1, 2, and $\mathbf{3}$ exhibit luminescence properties. We hope that this new BPPT ligand can obtain more novel structures. Studies toward the preparation of new $\mathrm{CPs}$ or MOFs, especially further studies of luminescence properties including the three complexes, are underway.

Author Contributions: Y.-S.Y. designed the research and wrote the manuscript. H.-Y.J., M.Y., and G.Z. performed the experiments. D.-Z.L. and Y.-B.Z. participated in analyzing data and contributed to the revisions of the manuscript. All authors have read and agreed to the published version of the manuscript.

Funding: This research was funded by Wuhan Textile University, grant number: 195014 and 017/192223; Hubei Superior and Distinctive Discipline Group of "Mechatronics and Automobiles" (No. XKQ2019009); Natural Science Foundation of Hubei Province (2016CFB334) and National Natural Science Foundation of China (No. 21204087).

Acknowledgments: We acknowledge Shiping Yan from Nankai Univerisity and Gongjun Chen from Shandong Normal University, they provide the technical support and help us analysis the results.

Conflicts of Interest: The authors declare no conflict of interest.

\section{References}

1. Wang, Q.; Astruc, D. State of the Art and Prospects in Metal-Organic Framework (MOF)-Based and MOF-Derived Nanocatalysis. Chem. Rev. 2020, 120, 1438-1511. [CrossRef] [PubMed]

2. Yin, Z.; Wan, S.; Yang, J.; Kurmoo, M.; Zeng, M.-H. Recent advances in post-synthetic modification of metal-organic frameworks: New types and tandem reactions. Coord. Chem. Rev. 2019, 378, 500-512. [CrossRef]

3. Wang, X.-S.; Cao, R. Multifunctional metal-organic framework catalysts: Synergistic catalysis and tandem reactions. Chem. Soc. Rev. 2017, 46, 126-157. 
4. Rogge, S.M.J.; Bavykina, A.; Hajek, J.; Garcia, H.; Olivos-Suarez, A.I.; Sepúlveda-Escribano, A.; Vimont, A.; Clet, G.; Bazin, P.; Kapteijn, F.; et al. Metal-organic and covalent organic frameworks as single-site catalysts. Chem. Soc. Rev. 2017, 46, 3134-3184. [CrossRef] [PubMed]

5. Liu, J.; Chen, L.; Cui, H.; Zhang, J.; Zhang, L.; Su, C.Y. Applications of metal-organic frameworks in heterogeneous supramolecular catalysis. Chem. Soc. Rev. 2014, 43, 6011-6061. [CrossRef]

6. Corma, A.; García, H.; Xamena, F.X.L. Engineering Metal Organic Frameworks for Heterogeneous Catalysis. Chem. Rev. 2010, 110, 4606-4655. [CrossRef]

7. Li, J.R.; Sculley, J.; Zhou, H.C. Metal Organic Frameworks for Separations. Chem. Rev. 2012, 112, 869-932. [CrossRef]

8. Voorde, B.V.; Bueken, B.; Denayer, J.; Vos, D.D. Adsorptive separation on metal-organic frameworks in the liquid phase. Chem. Soc. Rev. 2014, 43, 5766-5788. [CrossRef]

9. Kupgan, G.; Abbott, L.J.; Hart, K.E.; Colina, C.M. Modeling Amorphous Microporous Polymers for $\mathrm{CO}_{2}$ Capture and Separations. Chem. Rev. 2018, 118, 5488-5538. [CrossRef]

10. Pan, M.; Liao, W.-M.; Yin, S.-Y.; Sun, S.-S.; Su, C.-Y. Single-Phase White-Light-Emitting and Photoluminescent Color-Tuning Coordination Assemblies. Chem. Rev. 2018, 118, 8889-8935.

11. Kreno, L.E.; Leong, K.; Farha, O.K.; Allendorf, M.; Duyne, R.P.V.; Hupp, J.T. Metal-Organic Framework Materials as Chemical Sensors. Chem. Rev. 2012, 112, 1105-1125. [CrossRef] [PubMed]

12. Cui, Y.; Yue, Y.; Qian, G.; Chen, B. Luminescent Functional Metal-Organic Frameworks. Chem. Rev. 2012, 112, 1126-1162. [CrossRef] [PubMed]

13. Horcajada, P.; Gref, R.; Baati, T.; Allan, P.K.; Maurin, G.; Couvreur, P.; Férey, G.; Morris, R.E.; Serre, C. Metal-Organic Frameworks in Biomedicine. Chem. Rev. 2012, 112, 1232-1268. [CrossRef] [PubMed]

14. Kirchon, A.; Feng, L.; Drake, H.F.; Josepha, E.A.; Zhou, H.-C. From fundamentals to applications: A toolbox for robust and multifunctional MOF materials. Chem. Soc. Rev. 2018, 47, 8611-8638. [CrossRef] [PubMed]

15. Tan, Y.X.; Wang, F.; Zhang, J. Design and synthesis of multifunctional metal-organic zeolites. Chem. Soc. Rev. 2018, 47, 2130-2144. [CrossRef]

16. Espallargas, G.M.; Coronado, E. Magnetic functionalities in MOFs: From the framework to the pore. Chem. Soc. Rev. 2018, 47, 533-557. [CrossRef]

17. Vleet, M.J.V.; Weng, T.; Li, X.; Schmidt, J.R. In Situ, Time-Resolved, and Mechanistic Studies of Metal-Organic Framework Nucleation and Growth. Chem. Rev. 2018, 118, 3681-3721. [CrossRef]

18. Woodward, A.N.; Kolesar, J.M.; Hall, S.R.; Saleh, N.A.; Jones, D.S.; Walter, M.G. Thiazolothiazole Fluorophores Exhibiting Strong Fluorescence and Viologen-Like Reversible Electrochromism. J. Am. Chem. Soc. 2017, 139, 8467-8473. [CrossRef]

19. Zhai, Z.W.; Yang, S.H.; Luo, P.; Li, L.K.; Du, C.X.; Zang, S.Q. Dicarboxylate-Induced Structural Diversity of Luminescent Zn(II)/Cd(II) Metal-Organic Frameworks Based on the 2,5-Bis(4-pyridyl)thiazolo[5,4-d]thiazole Ligand. Eur. J. Inorg. Chem. 2019, 2019, 2725-2734. [CrossRef]

20. Yuan, F.; Wang, T.T.; Hu, H.M.; Li, C.T.; Zhou, C.S.; Wang, X.; Xue, G. Two luminescent d 10 metal coordination polymers assembled from a semirigid terpyridyl carboxylate ligand with high selective detecting of $\mathrm{Cu}^{2+}$, $\mathrm{Cr}_{2} \mathrm{O}_{7}{ }^{2-}$ and acetone. J. Solid. State. Chem. 2017, 251, 79-89. [CrossRef]

21. Xu, B.; Lu, J.; Cao, R. Anion-Assisted Structural Variation of Cadmium Coordination Polymers: From 2D $\rightarrow$ 3D Inclined Polycatenation to 2D $\rightarrow$ 3D Polythreading. Cryst. Growth Des. 2009, 9, 3003-3005. [CrossRef]

22. Guo, J.; Sun, D.; Zhang, L.; Yang, Q.; Zhao, X.; Sun, D. 1D Looped Chain, 1D Tube-like Chain, and 3D Inorganic-Organic Hybrid Coordination Polymers Assembled from 1,6-Di(triazole-1-yl-methyl)-4-R-phenol and Cadmium(II) Thiocyanate. Cryst. Growth Des. 2008, 8, 1599-1604.

23. Biswal, B.P.; Becker, D.; Chandrasekhar, N.; Seenath, J.S.; Paasch, S.; Machill, S.; Hennersdorf, F.; Brunner, E.; Weigand, J.J.; Berger, R.; et al. Exploration of Thiazolo[5,4-d]thiazole Linkages in Conjugated Porous Organic Polymers for Chemoselective Molecular Sieving. Chem. Eur. J. 2018, 24, 10868-10875. [CrossRef]

24. Lin, H.; Maggard, P.A. Ligand-Mediated Interconversion of Multiply-Interpenetrating Frameworks in $\mathrm{Cu}^{\mathrm{I}} / \mathrm{Re}^{\mathrm{VI}} \mathrm{I}$-Oxide Hybrids. Inorg. Chem. 2009, 48, 8940-8946. [CrossRef]

25. Li, D.X.; Chen, M.M.; Li, F.L.; Ren, Z.G.; Wu, B.; Lang, J.P. Substituent groups-driven construction of two different $\mathrm{Cd}(\mathrm{II})$ coordination polymers from $\mathrm{CdSO}_{4}$, tetrakis(4-pyridyl)cyclobutane and 5-R-1,3-benzenedicarboxylates. Inorg. Chem. Commun. 2013, 35, 302-306. [CrossRef] 
26. Chen, X.L.; Cui, H.L.; Yang, H.; Liu, L.; Wang, X.; Ren, Y.X.; Wang, J.J.; Han, B. A Zinc(II) Coordination Polymer Based on a Polycarboxylate Ligand: Synthesis, Crystal Structure, Photoluminescence and Photocatalysis. Chin. J. Struct. Chem. 2019, 12, 2148-2154.

27. Wang, X.L.; Qin, C.; Wang, E.B.; Xu, L.; Su, Z.M.; Hu, C.W. Interlocked and interdigitated architectures from self-assembly of long flexible ligands and cadmium salts. Angew. Chem. Int. Ed. 2004, 43, 5036-5040. [CrossRef]

28. Johnson, J.R.; Rotenberg, D.H.; Ketcham, R. Thiazolothiazoles. II. Parent heterocycle and its carboxylic and amino derivatives. J. Am. Chem. Soc. 1970, 92, 4046-4050. [CrossRef]

29. Sheldrick, G.M. SHELXS 97, Program for the Solution of Crystal Structures; University of Götingen: Götingen, Germany, 1997.

30. Sheldrick, G.M. SHELXL 97, Program for the Refinement of Crystal Structures; University of Götingen: Götingen, Germany, 1997.

Sample Availability: Samples of the compounds are not available from the authors.

(C) 2020 by the authors. Licensee MDPI, Basel, Switzerland. This article is an open access article distributed under the terms and conditions of the Creative Commons Attribution (CC BY) license (http://creativecommons.org/licenses/by/4.0/). 